\title{
FREQUENCY SPECTRUM GENERATED BY THYRISTOR CONTROL
}

\author{
J. K. HALL and N. C. JONES \\ Loughborough University of Technology, Loughborough, Leics. U.K.
}

(Received October 30, 1973; in final form December 19, 1973)

\begin{abstract}
This paper describes the measured harmonics in the load currents of thyristor circuits and shows that with firing angle control the harmonic amplitudes decrease sharply with increasing harmonic frequency, but that they extend to very high harmonic orders of around 6000 . The amplitudes of the harmonics are a maximum for a firing delay angle of around $90^{\circ}$.

Integral cycle control produces only low order harmonics and sub-harmonics.

It is also shown that with firing angle control apparently random inter-harmonic noise is present and that the harmonics fall below this noise level at frequencies of approximately $250 \mathrm{KHz}$ for a switched $50 \mathrm{~Hz}$ waveform and for the resistive load used. The noise amplitude decreases with increasing frequency and is a maximum with $90^{\circ}$ firing delay.
\end{abstract}

\section{INTRODUCTION}

Thyristors are now widely used for control of power in both d.c. and a.c. circuits. ${ }^{1}$ The advantages of relatively small size, low losses and fast switching speeds have contributed to the vast growth in application since their introduction, when they were basically a solid-state replacement for mercury-arc rectifier devices. As a result, attention has been focussed on the inherent problems produced by thyristor control, some of which are a perpetuation of those with mercury-arc rectifiers. These are now giving cause for greater concern owing to the scale of usage. The majority of applications utilise a.c. line commutation and only these are considered here.

The switching action of the thyristors (or triac) results in non-sinusoidal currents being drawn from the a.c. supply system. Harmonics and noise are thereby injected into the power supply and give rise to conducted interference with other electronic and communications equipment. ${ }^{2-4}$ Unless the apparatus is screened, radiated interference also occurs. The effects of interference are varied, from malfunctioning of low-level micrologic circuits and triggering of other separately-controlled thyristors to disturbance of radio and T.V. reception. 5 The elimination of these effects is an important objective. Ways of suppressing the harmonics and noise have been devised using, on the one hand, greatly improved discrete components and on the other, composite devices containing within one component resistance, capacitance and inductance. ${ }^{6,7}$ Literature on the subject tends to assume that noise is due to the high frequency harmonics generated by thyristor switch-on and the design of suppression components is based on this. This investigation has been performed in order to establish the validity of this assumption, since it is believed that there may be a number of perhaps separate sources of noise in thyristor circuits. Four well-known circuits have been examined, both experimentally using a spectrum analyser and by a theoretical analysis of the waveforms to define the harmonic spectrum expected. The presence of random noise, in addition to the expected harmonics, is demonstrated.

\section{EXPERIMENTAL DETAILS}

The four single-phase circuits investigated were a single-thyristor half-wave rectifier, a triac a.c. controller with firing angle control, a thyristor full-wave rectifier bridge, and a triac a.c. controller with integral cycle control. The triac functions as two thyristors in anti-parallel, but has a single gate electrode. The load current waveforms were examined and these have the form shown in Figure 1. From the conducted interference viewpoint, the supply current is of interest. The supply current is the same as the load current in all circuits except the rectifier bridge, in which case it has the same form as that of the triac with firing angle control. 
(a)



(b)

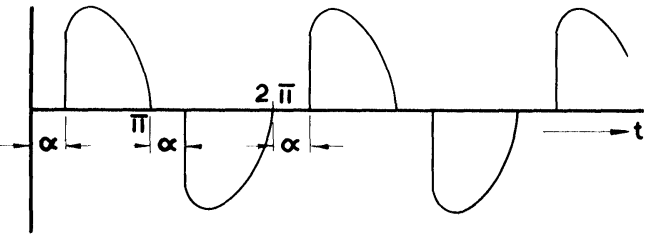

(c)



(d)



(a) Single thyristor, half-wove rectifier.

(b) Vorioble o.c. by trioc with firing ongle control.

(c) Thyristor bridge, full-wove rectifier.

(d) Variable a.c. by triac with integral cycle control.

FIGURE 1 Output waveforms for the circuits examined.

The basic measuring circuit is shown in Figure 2. This consists of a resistive load of low inductance supplied from single-phase a.c. mains through the thyristor controller. In series with the load is a sampling resistor of very low inductance, across which a voltage proportional to load current is taken. This is fed to a Hewlett-Packard spectrum analyser ${ }^{8}$ and an oscilloscope. This arrangement is more suitable for study of the low frequency harmonics, since combined symmetrical and asymmetrical radiofrequency components are indicated. For detailed study of the radio-frequency voltages, the techniques of $\mathrm{BS} 800^{9}$ are more appropriate. The complete test circuit is installed in a screened room in order to reduce external interference.

The principle of the spectrum analyser is that the waveform under examination is swept by a narrowband filter $(10 \mathrm{~Hz}$ minimum bandwidth) controlled by a variable frequency oscillator. The output is displayed on a storage tube whose vertical axis represents amplitude, and horizontal axis frequency.

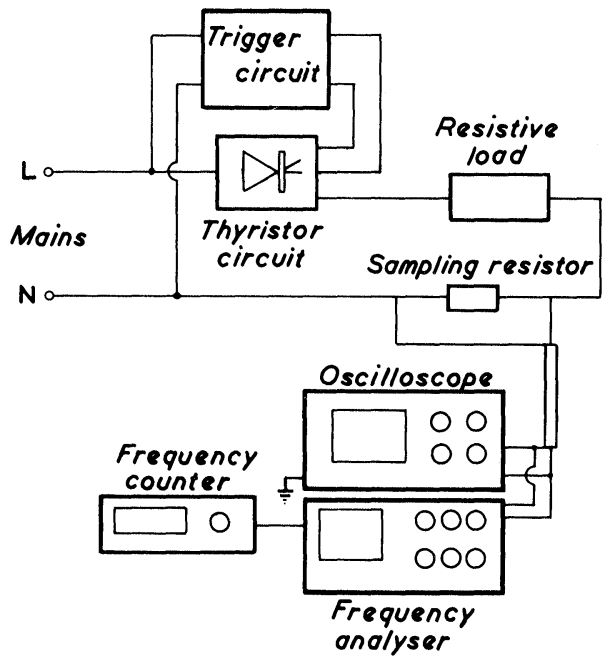

FIGURE 2 Basic measuring circuit.

A typical trace is shown in Figure 3, where the individual harmonics at $50 \mathrm{~Hz}$ intervals can easily be seen. Controls on the analyser enable the bandwidth of the filter, the swept frequency limits and sweep time to be controlled. A variable attenuator adjusts the input signal appropriately. The frequency counter (Figure 2) gives a direct indication of the frequency band being swept, thus enabling the specific harmonic frequencies displayed to be interpreted. It should be noted that the spectrum analyser indicates the magnitudes of the harmonics present in the waveform, but not their phase in relation to the fundamental.

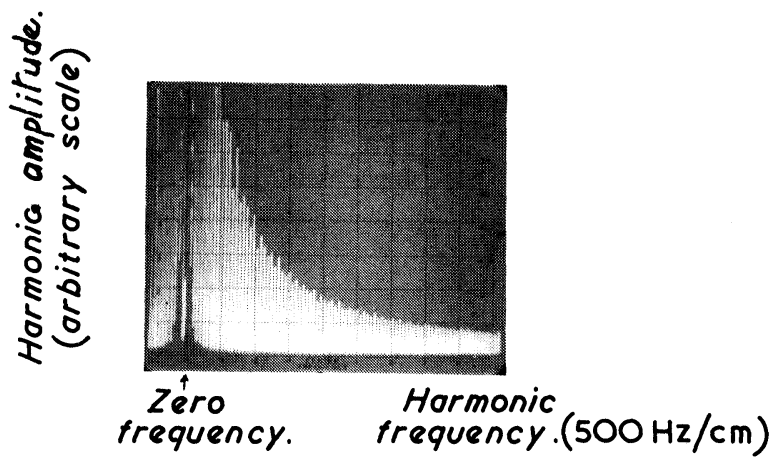

FIGURE 3 Harmonic spectrum trace from the spectrum analyser. 


\section{THEORETICAL CONSIDERATIONS}

The current waveforms of Figure 1 can be resolved into the harmonic components present by use of the general Fourier Series:-

$$
f(t)=A_{0}+\sum_{n=1}^{n=\infty} C_{n} \sin \left(n \omega t .+\psi_{n}\right)
$$

where $f(t)$ is the waveform function under consideration,

$\mathrm{n}$ is the harmonic order $-1,2,3 \ldots \ldots \ldots$

$\mathrm{A}_{0}$ is the direct component

$\mathrm{C}_{\mathrm{n}}$ is the amplitude of the nth harmonic $\psi_{\mathrm{n}}$ is the phase of the nth harmonic.

The expansion is calculated from:

$$
C_{n}=\left(A_{n}^{2}+B_{n}^{2}\right)^{1 / 2}
$$

where

$$
A_{n}=\frac{1}{\pi} \int_{0}^{2 \pi} f(t) \cos n \omega t d(\omega t)
$$

and

$$
\begin{aligned}
& B_{n}=\frac{1}{\pi} \int_{0}^{2 \pi} f(t) \sin n \omega t d(\omega t) \\
& \psi_{n}=\tan ^{-1} \frac{A_{n}}{B_{n}}
\end{aligned}
$$

The mean or d.c. level is given by:

$$
A_{0}=\frac{1}{2 \pi} \int_{0}^{2 \pi} \mathrm{f}(\mathrm{t}) \mathrm{dt}
$$

The constants $A_{n}, B_{n}$ and $A_{0}$ for each waveform are as follows:

a) Half-wave rectifier:

$n$th harmonic of the supply frequency $(n=2,3,4, \ldots)$ :

$$
\begin{aligned}
& A_{n}=\frac{\hat{I}}{2 \pi}\left[\frac{\cos (1+n) \alpha}{1+n}+\frac{\cos (1-n) \alpha}{1-n}+\frac{2(-1)^{n}}{1-n^{2}}\right] \\
& B_{n}=\frac{\hat{I}}{2 \pi}\left[\frac{\sin (1+n) \alpha}{1+n}-\frac{\sin (1-n) \alpha}{1-n}\right]
\end{aligned}
$$

d.c. component:

$$
\mathrm{A}_{0}=\frac{\hat{\mathrm{I}}}{2 \pi}(\cos \alpha+1)
$$

fundamental:

$$
\mathrm{A}_{1}=\frac{\hat{\mathrm{I}}}{2 \pi}\left[\frac{\cos 2 \alpha-1}{2}\right]
$$

$$
\mathrm{B}_{1}=\frac{\hat{\mathrm{I}}}{2 \pi}\left[\pi-\alpha+\frac{\sin 2 \alpha}{2}\right]
$$

where $\alpha$ is the firing delay angle, and $\hat{I}$ is the peak value of the sinusoidal current.

b) Triac with firing delay: $n$th harmonic of the supply frequency $(n=3,5,7, \ldots)$ :

$$
\begin{aligned}
& A_{n}=\frac{\hat{I}}{\pi}\left[\frac{\cos (n+1) \alpha}{n+1}-\frac{\cos (n-1) \alpha}{n-1}+\frac{2}{n^{2}-1}\right] \\
& B_{n}=\frac{\hat{I}}{\pi}\left[\frac{\sin (n+1) \alpha}{n+1}-\frac{\sin (n-1) \alpha}{n-1}\right]
\end{aligned}
$$

Even harmonics are absent, since $A_{n}=B_{n}=0$ with $\mathrm{n}=2,4,6, \ldots$ during the derivation.

d.c. component:

$$
\mathrm{A}_{0}=0
$$

fundamental:

$$
\begin{aligned}
& \mathrm{A}_{1}=\frac{\hat{\mathrm{I}}}{\pi}\left[\frac{\cos 2 \alpha-1}{2}\right] \\
& \mathrm{B}_{1}=\frac{\hat{\mathrm{I}}}{\pi}\left[\pi-\alpha+\frac{\sin 2 \alpha}{2}\right]
\end{aligned}
$$

c) Full-wave rectifier:

$n$th harmonic of the supply frequency $(n=2,4,6, \ldots)$ :

$$
\begin{aligned}
& A_{n}=\frac{\hat{I}}{\pi}\left[\frac{\cos (1+2 n) \alpha}{1+2 n}+\frac{\cos (1-2 n) \alpha}{1-2 n}+\frac{2}{1-4 n^{2}}\right] \\
& B_{n}=\frac{\hat{I}}{\pi}\left[\frac{\sin (1+2 n) \alpha}{1+2 n}-\frac{\sin (1-2 n) \alpha}{1-2 n}\right]
\end{aligned}
$$

Odd harmonics are absent, since $A_{n}=B_{n}=0$ with $\mathrm{n}=3,5,7, \ldots$ during the derivation.

d.c. component:

$$
A_{0}=\frac{\hat{I}}{\pi}[1+\cos \alpha]
$$

fundamental:

$$
\mathrm{A}_{1}=\mathrm{B}_{1}=0
$$

d) Triac with integral-cycle control: $\mathrm{nth}$ harmonic of the output waveform $(\mathrm{n}=1,2,3, \ldots$ $\mathrm{T}, 3 \mathrm{~T}, 5 \mathrm{~T}, \ldots$ ):

$$
A_{n}=\frac{\hat{I} T}{\pi\left(n^{2}-T^{2}\right)}\left[\cos \frac{(2 n \pi N)}{T}-1\right]
$$


TABLE I

Measured harmonic amplitudes (as a \% of mains) with varying firing angle for the half-wave rectifier circuit.

\begin{tabular}{lllllll}
\hline Firing angle $\alpha$ & \multicolumn{5}{c}{ Amplitude at the stated harmonic frequency (Hz) } \\
\cline { 2 - 7 } & $\begin{array}{lllllll}\text { (Degrees) } \\
\text { (fundamental) }\end{array}$ & $\begin{array}{l}100 \\
(2 \mathrm{nd})\end{array}$ & $\begin{array}{l}150 \\
(3 \mathrm{rd})\end{array}$ & $\begin{array}{l}500 \\
(10 \mathrm{th})\end{array}$ & $\begin{array}{l}1000 \\
(20 \mathrm{th})\end{array}$ & $\begin{array}{l}2000 \\
(40 \mathrm{th})\end{array}$ \\
\hline 18 & 50.0 & 22.0 & 1.4 & 1.0 & 0.4 & 0.20 \\
54 & 43.0 & 27.0 & 10.0 & 2.4 & 1.0 & 0.45 \\
90 & 28.0 & 23.0 & 15.0 & 3.0 & 1.2 & 0.60 \\
126 & 11.0 & 10.0 & 9.0 & 2.5 & 1.0 & 0.45 \\
162 & 1.3 & 1.5 & 1.8 & 1.0 & 0.4 & 0.20 \\
\hline
\end{tabular}

$$
\mathrm{B}_{\mathrm{n}}=\frac{\hat{\mathrm{I} T}}{\pi\left(\mathrm{n}^{2}-\mathrm{T}^{2}\right)} \sin \frac{(2 \mathrm{n} \pi \mathrm{N})}{\mathrm{T}}
$$

Putting $n=1$ gives the coefficients for the fundamental frequency at the load; that is, the lowest subharmonic of the supply frequency $(=1 / \mathrm{T} \times$ supply frequency). Other coefficients are given for frequencies up to that of the supply voltage. The coefficients for the supply frequency harmonic of the load current $(n=T)$ :

$$
\begin{aligned}
& \mathrm{A}_{\mathrm{T}}=0 \\
& \mathrm{~B}_{\mathrm{T}}=\hat{\mathrm{I}} \frac{\mathrm{N}}{\mathrm{T}}
\end{aligned}
$$

For higher frequencies:

$$
A_{n}=B_{n}=0
$$

for harmonics which are even multiples of the supply frequency $(n=2 T, 4 T, 6 \mathrm{~T}, \ldots)$.

d.c. component:

$$
\mathrm{A}_{0}=0
$$

where $T$ is the number of supply cycles in a period of integral-cycle control, and $\mathrm{N}$ is the number of ' $\mathrm{ON}$ ' cycles in a period of integral-cycle control. The individual harmonic amplitudes $C_{n}$ and phases, $\psi_{n}$ (when required) were calculated with the aid of a computer for assumed values of $\mathrm{n}$ and firing delay $\alpha$ or on/off cycle ratio, as appropriate.

\section{RESULTS AND DISCUSSION}

It is appropriate to consider the low frequency and high frequency harmonic components of the current waveforms separately. The individual thyristor circuits are taken in order.

\section{a) Thyristor Half-Wave Rectifier}

The results of measurements of specific low frequency harmonics generated with the single thyristor control are given in Table I. They are shown as a function of firing angle and it is apparent that the harmonics are a maximum with a firing delay of $90^{\circ}$ A detailed representation of the harmonics present up to $1900 \mathrm{~Hz}$ with a firing delay of $90^{\circ}$ is shown in Figure 4. Both measured and computed values are given; it can be seen that these agree very well.

Measurements of the high frequency components up to $300 \mathrm{kHz}$ were made. the spectrum analyser indicated the presence of random noise between the predicted lines of the harmonic spectrum. Table II summarises the measured amplitudes of the harmonics at $50 \mathrm{kHz}$ and $100 \mathrm{kHz}$, together with the interharmonic noise level near these frequencies, both as a function of firing angle. As is to be expected from the low frequency harmonic results, the high frequency harmonics have a maximum amplitude with the firing angle set at $90^{\circ}$. However, the same is true of the noise, within experimental error, though the effect is not so pronounced. Table III shows measurements of harmonics and noise up to the

TABLE II

Dependence of high frequency harmonics and noise on firing angle for the half-wave rectifier circuit.

(Values in $\mu \mathrm{V}$ across a $1 \mathrm{ohm}$ sampling resistor; $0.7 \mathrm{~V}$ obtained with full mains applied)

\begin{tabular}{llrlc}
\hline $\begin{array}{l}\text { Firing angle } \\
\text { (Degrees) }\end{array}$ & \multicolumn{2}{c}{$\begin{array}{c}\text { At frequency } \\
\text { Harmonics }\end{array}$} & Noise & \multicolumn{2}{c}{$\begin{array}{l}\text { At frequency } 100 \mathrm{kHz} \\
\text { Harmonics }\end{array}$} & Noise \\
\hline 18 & 20 & 8 & 2 & 2 \\
54 & 60 & 15 & 20 & 8 \\
90 & 80 & 15 & 30 & 8 \\
126 & 70 & 15 & 25 & 10 \\
162 & 35 & 8 & 12 & 5 \\
\hline
\end{tabular}




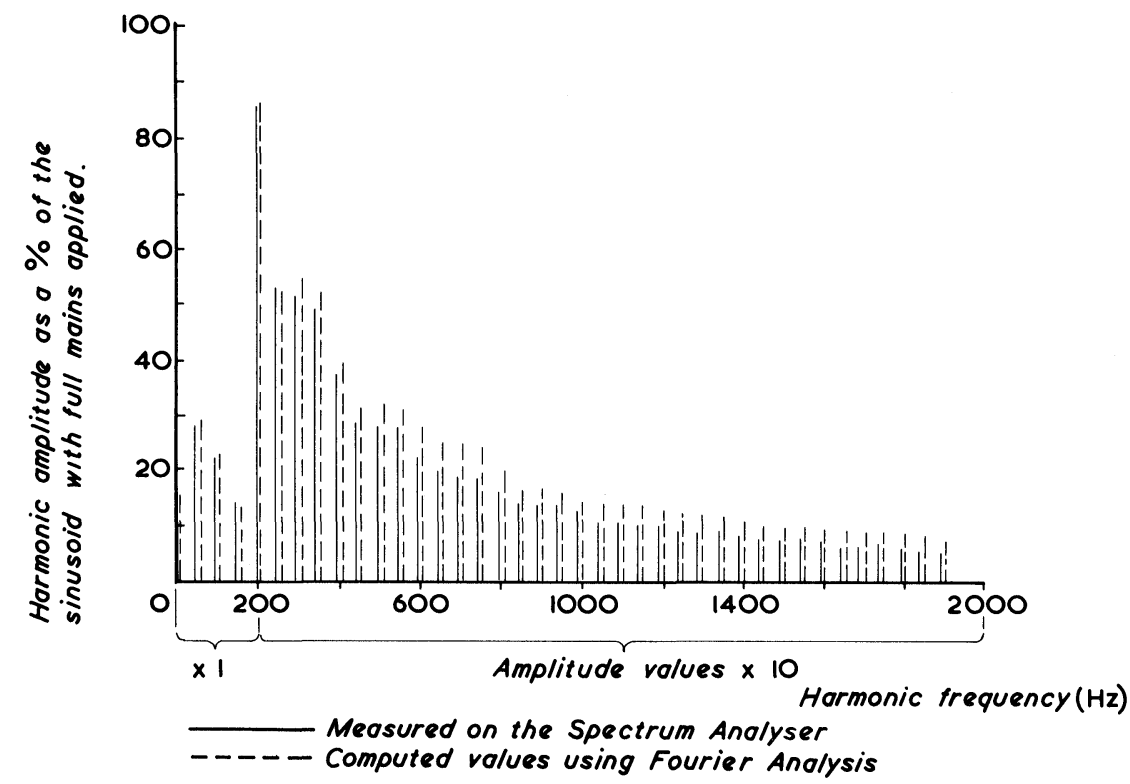

FIGURE 4 Low-frequency harmonics from the half-wave rectifier circuit $\left(90^{\circ}\right.$ firing delay).

TABLE III

Measured high frequency harmonic amplitudes and noise for the half-wave rectifier circuit with $90^{\circ}$ firing delay.

( Amplitudes in $\mu \mathrm{V}$ across a $5 \mathrm{ohm}$ sampling resistor: 3.7V obtained with full mains applied).

\begin{tabular}{lccc}
\hline $\begin{array}{l}\text { Frequency } \\
\text { (kHz) }\end{array}$ & $\begin{array}{l}\text { Harmonic } \\
\text { order }\end{array}$ & $\begin{array}{l}\text { Harmonic } \\
\text { amplitude }\end{array}$ & $\begin{array}{l}\text { Noise } \\
\text { amplitude }\end{array}$ \\
\hline 10 & 200 & 4000 & 100 \\
30 & 600 & 1000 & 30 \\
60 & 1200 & 300 & 25 \\
100 & 2000 & 150 & 20 \\
130 & 2600 & 110 & 20 \\
160 & 3200 & 70 & 20 \\
200 & 4000 & 50 & 15 \\
230 & 4600 & 40 & 15 \\
260 & 5200 & 0 & 10 \\
300 & 6000 & - & 10 \\
\hline
\end{tabular}

highest frequencies considered. Both harmonics and noise decrease with increasing harmonic order, though the noise decreases at a much lesser rate. At about $300 \mathrm{kHz}$ the harmonic amplitudes are such that they cannot be distinguished from the noise.

\section{b) Triac with Firing Delay}

Measurements similar to those made with the single thyristor were repeated for the triac a.c. controller and the results are shown in Tables IV and V. Table IV demonstrates again that the harmonic amplitudes are a maximum with $90^{\circ}$ firing delay. As predicted by the Fourier Analysis, only odd harmonics are present owing to the symmetry of positive and negative half-cycles (Figure 1b). Table V again illustrates the decreasing harmonic and noise amplitudes with increasing harmonic frequency and the merging of the harmonics into the noise around $300 \mathrm{kHz}$.

TABLE IV

Measured harmonic amplitudes (as a $\%$ of mains) with varying firing angle for the triac circuit.

\begin{tabular}{lllllll}
\hline Firing angle $\alpha$ & \multicolumn{5}{c}{ Amplitude at the stated harmonic frequency (Hz) } \\
\cline { 2 - 7 } & 50 & 150 & 250 & 550 & 1050 & 2050 \\
(Degrees) & (fundamental) & $(3 \mathrm{rd})$ & $(5 \mathrm{th})$ & $(11 \mathrm{th})$ & $(21 \mathrm{st})$ & $(41 \mathrm{st})$ \\
\hline 18 & 98 & 4 & 3.0 & 2.0 & 1.0 & 0.4 \\
54 & 90 & 18 & 10.0 & 3.5 & 1.8 & 1.0 \\
90 & 58 & 30 & 10.0 & 9.0 & 3.5 & 1.2 \\
126 & 48 & 18 & 10.0 & 4.5 & 1.5 & 1.0 \\
162 & 2 & 2 & 2.5 & 1.9 & 0.5 & 0.4 \\
\hline
\end{tabular}


TABLE V

Measured high frequency harmonic amplitudes and noise for the triac circuit with $90^{\circ}$ firing delay. (Amplitudes in $\mu \mathrm{V}$ across a $5 \mathrm{ohm}$ sampling resistor; $3.7 \mathrm{~V}$ obtained with full mains applied).

\begin{tabular}{lccc}
\hline $\begin{array}{l}\text { Frequency } \\
(\mathrm{kHz})\end{array}$ & $\begin{array}{l}\text { Approx. harmonic } \\
\text { order }\end{array}$ & $\begin{array}{l}\text { Harmonic } \\
\text { amplitude }\end{array}$ & $\begin{array}{l}\text { Noise } \\
\text { amplitude }\end{array}$ \\
\hline 10 & 200 & 3500 & 100 \\
30 & 600 & 800 & 50 \\
60 & 1200 & 250 & 40 \\
100 & 2000 & 140 & 40 \\
130 & 2600 & 80 & 40 \\
160 & 3200 & 80 & 30 \\
200 & 4000 & 50 & 25 \\
230 & 4600 & 30 & 25 \\
260 & 5200 & - & 20 \\
\hline
\end{tabular}

\section{c) Thyristor Full-Wave Rectifier}

The low-order harmonics measured in the d.c. load current waveforms (Figure 1c) are shown in Table VI as a function of firing angle. Only even harmonics of the supply frequency are present, $100 \mathrm{~Hz}$ being the fundamental ripple frequency. The harmonics of this ripple frequency exhibit their maxima at $90^{\circ}$ firing delay. As mentioned earlier, the a.c. line current drawn has the same waveform as is produced by triac control (Figure 1b), so that Tables IV and V provide the relevant information for the rectifier supply current.

\section{d) Triac with Integral-Cycle Control.}

The zero-voltage switching of integral-cycle control results in the absence of high frequency harmonics, and herein lies the advantage of the method. This is illustrated in Figure 5 which shows results obtained with equal on and off periods. Change in the ratio on/off cycles will produce a variation in harmonic amplitudes, but the general pattern of a predominance of low order harmonics and subharmonics of the supply frequency is well demonstrated. The presence of subharmonics is disadvantageous with loads of a low thermal time constant, for which this method of control may be inappropriate. No measurements have been taken at the high frequency end of the spectrum.

Only measured results have been quoted in most cases since Figure 4 shows that these agree fairly closely with those computed from the Fourier Analysis. An infinite rate of current rise at thyristor turn-on with firing angle control has been assumed for the analysis though this is not attained in practice. For this reason the correlation is less good at the higher frequencies. The presence of the interharmonic noise with firing angle control is the most outstanding feature observed. The fact that this exceeds the harmonics at frequencies above about $260 \mathrm{kHz}$ is very significant. Tests with the single thyristor in circuit, with the triggering signal removed, and carrying d.c. revealed only minimal noise, showing that most of the noise is generated by the thyristor control and not the sampling resistor or other peripheral equipment.

\section{CONCLUSIONS}

The measurements have confirmed the presence of harmonics in the load currents of the thyristor circuits examined and have defined their pattern. With firing angle control the harmonic amplitudes decrease sharply with increasing harmonic frequency but they extend to very high harmonic orders or around 6000 . The amplitudes of the harmonics measured are a maximum for a firing delay angle of around $90^{\circ}$, though this does not necessarily apply to all the harmonics present. ${ }^{10}$ Integral cycle control produces only low-order harmonics and subharmonics. Computed results have not been given in every case as correlation with measurements is good, though this is less so at the highest frequencies. With firing angle control, apparently random, inter-

TABLE VI

Measured harmonic amplitudes (as a \% of mains) with varying firing angle for the full-wave bridge circuit.

\begin{tabular}{lllllll}
\hline Firing angle $\alpha$ & \multicolumn{5}{c}{ Amplitude at the stated harmonic frequency $(\mathrm{Hz})$} \\
\cline { 2 - 7 } & $\begin{array}{l}100 \\
\text { (Degrees) }\end{array}$ & $\begin{array}{l}200 \\
\text { (2nd) }\end{array}$ & $\begin{array}{l}300 \\
\text { (4th) }\end{array}$ & $\begin{array}{l}\text { (6th) } \\
(100)\end{array}$ & $\begin{array}{l}1000 \\
(20 \text { th })\end{array}$ & $\begin{array}{l}2000 \\
(40 \text { th) }\end{array}$ \\
\hline 18 & 50.0 & 12.0 & 6.0 & 2.0 & 1.5 & 0.6 \\
54 & 60.0 & 12.0 & 11.0 & 5.5 & 3.5 & 1.4 \\
90 & 45.0 & 20.0 & 12.0 & 7.0 & 4.0 & 1.5 \\
126 & 18.0 & 15.0 & 11.0 & 4.0 & 2.5 & 1.5 \\
162 & 2.5 & 2.5 & 2.5 & 2.0 & 1.2 & 0.5 \\
\hline
\end{tabular}




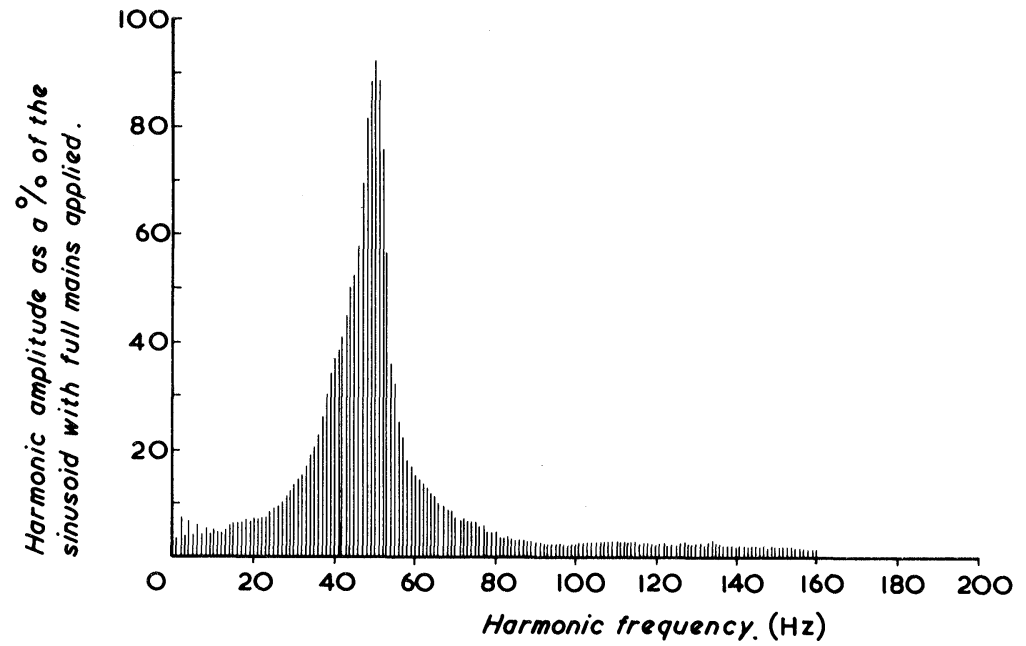

FIGURE 5 Harmonics from the integral-cycle a.c. control circuit (25:25 cycles on/off ratio).

harmonic noise is present, the harmonics falling below this noise level at frequencies of approximately $250 \mathrm{kHz}-300 \mathrm{kHz}$, for the resistive load used. The noise amplitude decreases with increasing frequency and is a maximum with $90^{\circ}$ firing delay. Investigation into the causes of noise generated by thyristor control is continuing.

\section{ACKNOWLEDGEMENT}

Acknowledgement is made of the experimental facilities provided by the Department of Electronic and Electrical Engineering, Loughborough University of Technology. The advice and encouragement of Professor D. S. Campbell is greatly appreciated.

\section{REFERENCES}

1 F. E. Gentry et al., Semiconductor Controlled Rectifiers, (Prentice-Hall 1964).

2 J. R. Taylor et al., Electronic Engineering, 43, 37-41 (August, 1971).

3 D. W. Matthias, IEEE Electromagnetic Compatibility Symposium Record, 29-34 (June, 1969).

4 A. A. Collie, IEE Electronics and Power, 18, 19-22 (January, 1972).

5 SCR Manual (5th Edition) General Electric Co. Chap. 17.

6 P. J. Harrop, Electron, No. 19, 13-14 (11 January, 1973).

7 H.P. Kaiserworth, Siemens Electronics Component Bulletin, VII, 49-52 (1972).

8 R. C. Keiter, Hewlett-Packard Journal 23, (1), 4-9 (September, 1971).

9 BS 800, Parts 1 and 3, 1972.

10 R. Smith, Electronic Engineering, 36, (442) 832-837 (1964). 



Submit your manuscripts at

http://www.hindawi.com
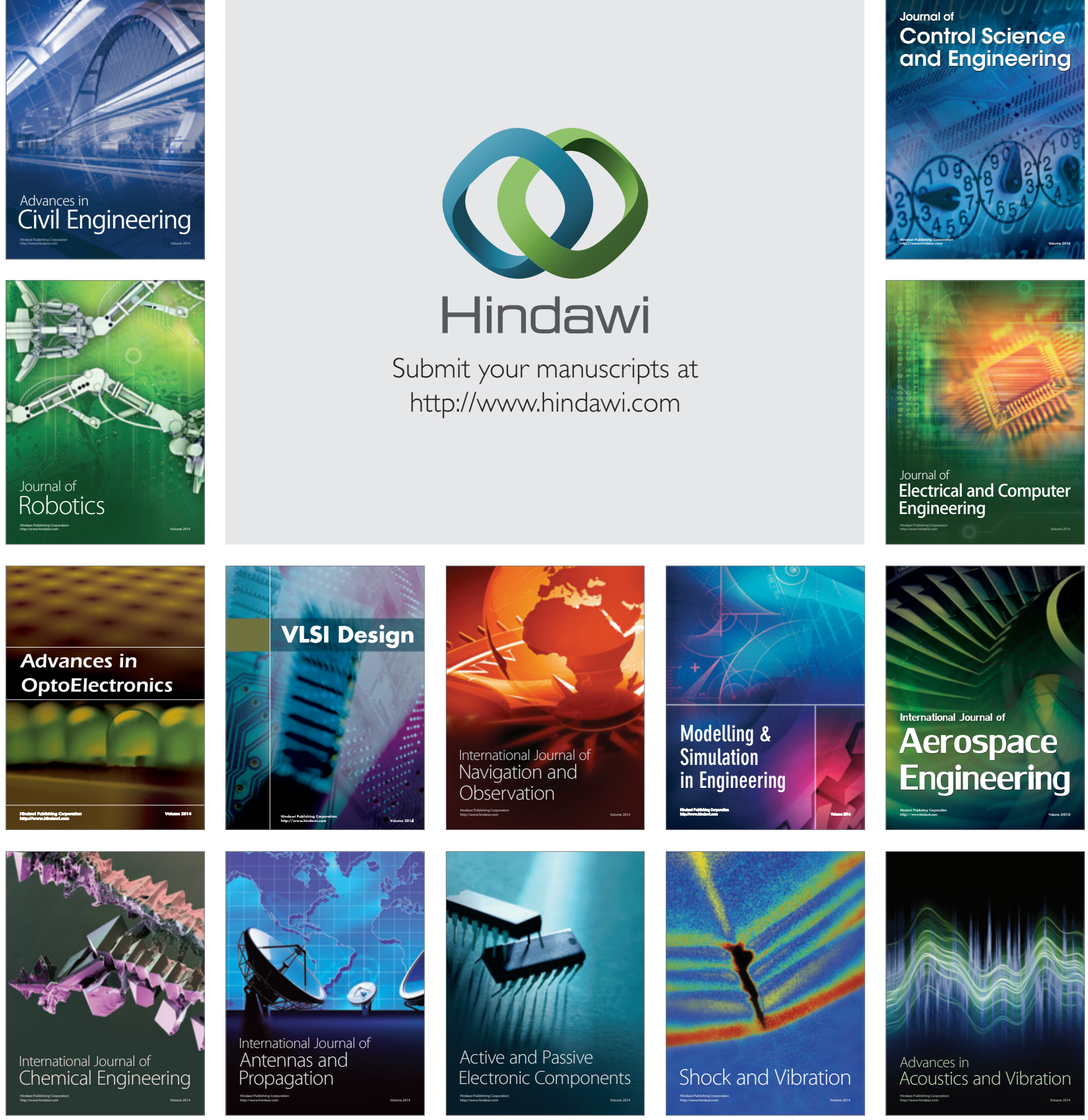